\title{
Mobile IPTV: Implications for Education
}

\begin{abstract}
Mobile IPTV (Internet Protocol Television) provides digital content which users watch as a television broadcast via the Internet on a mobile device. This paper presents the development of IPTV, Suan Dusit Internet Broadcasting, (SDIB) to mobile IPTV and discusses the implications for education. Mobile IPTV was developed as a prototype and designed to support users via wireless and mobile networks regardless of the mobile device. The system can be broadcasted through both live and video on demand (VOD) utilizing a mobile browser (smart phones, smart TVs, and tablets) and web browsers (Windows, Mac, and UNIX). The mobile IPTV prototype has been used and evaluated in this study. The results of student's behavior when using mobile phones in their learning found that the highest mobile use was for Facebook and Line to communicate and share information with their classmates. The results of student's attitudes towards using mobile phones in their learning found that the highest mobile use was for sharing information with classmates, sharing learning experiences on social networks, and using mobile phones to support their studies. The result of the IPTV and mobile IPTV system evaluation found that overall mobile IPTV had a higher user satisfaction than IPTV. Furthermore, mobile IPTV creates a good learning experience for the users. This paper provides guidelines in technical issues for helping educational institutions to develop mobile IPTV for education.
\end{abstract}

Pannee Suanpng

Faculty of Science \& Technology

Suan Dusit Rajabhat Univeristy

Bangkok, Thailand

dtechpannee@yahoo.com

\section{Keywords}

Mobile IPTV, IPTV, internet broadcasting, mobile learning, educational innovation

\section{Council for Innovative Research}

Peer Review Research Publishing System

Journal: International Journal of Computers \& Technology

Vol 11, No.3

editor@cirworld.com

www.cirworld.com, member.cirworld.com 


\section{INTRODUCTION}

Internet Protocol Television (IPTV) is defined as multimedia content - including text, graphics, audio and video files - over an IP network to reach a large number of users. It is a combination of modern technologies in computing, networking and storage to deliver content through an Internet Protocol (IP) network [1]. IPTV has changed the way users' access information and entertainment. It has been utilized in multiple sectors such as business, entertainment, communication, healthcare and education. IPTV has been integrated with e-Learning systems as a tool for supporting learning in education [2].

An example of IPTV implication for education, such as Suan Dusit Internet Broadcasting (SDIB), aims to use IPTV to develop new educational innovations in order to support distance and life-long learning for students and to increase learning channels for the delivery of information and knowledge to local communities [3-4].The IPTV system broadcasts four channels: children, video on demand, variety and radio, with more than seven hundred programs transmitted both through live and video on demand via computers and set top boxes (STB). The IPTV system was used in 80 pilot schools in Thailand. The result of the IPTV system evaluation in the pilot schools was highly satisfactory. Finally, a strategic plan of using IPTV as an educational innovation was developed [3][5].

However, the successful deployment of the IPTV application and services essentially depends on a wide range of supporting new technologies [6]. Currently, mobile telecommunication has evolved at an incredible pace worldwide. In developing countries, mobile penetration rates have long reached $100 \%$ [7].This increases the number of users - along with their portable devices - that can access information anywhere and anytime. Mobile technologies have become more powerful and pervasive and increasingly therefore mobile applications have become more important. They are being used in communication, business and education. According to an IDC survey [8], 70\% of organizations are currently deploying at least one mobile application [9].

Mobile technologies have several advantages such as context: the ability to acquire information about their learning environment presents a unique ability to personalize the learning opportunity. Mobility: learners can learn anywhere, anytime. Learning over time: lifelong learners especially need effective tools to organize and reflect via their mobile. Informality: the learner can use mobiles to search and share information more effectively during their learning process [20].

It will be a challenge to expanding IPTV to become mobile IPTV for supporting changing technology. Technology trends allow mobile IPTV to extend many IPTV services to mobile users [10-11]. Mobile IPTV technology is an application that allows users to transmit and receive multimedia content through an IP-based network with the support of security, mobility and interactivity [12]. Mobile IPTV refines mobile TV as an IP-based service that shifts content across anytime, anyplace and multiple devices [16].

There are four types of mobile TV technology approaches: mobile TV over IP, IPTV over mobile devices, cellular IPTV, and Internet IPTV [12]. Typical mobile IPTV architecture started from users receiving content via smart phones or wireless equipment. Technical challenges for developing mobile IPTV to be considered include heterogeneity of end-users' terminals and devices, wireless link bandwidths, wireless link radio characteristics, service coverage, middleware and scalable video coding, quality of service (QoS), quality of experience (QoE) and business issues [12-13].

Although mobile IPTV has been greatly researched in the areas of communication, networking, and human computer interfacing, little research has been done on how to apply it to educational environments [2][7][9][10][11][12][14]. Mobile technologies allow students to develop a personalized, learner-centered, situated, collaborative, ubiquitous and lifelong learning experience [13-14]. Mobile IPTV is an educational innovation that supports learning activities complementary to the range of instruments that teachers can employ in the educational system.

Mobile IPTV has several advantages in supporting teaching and learning such as students creating and sharing their own content [12-13], having more tools and functions to support their needs [18], ease of use and convenience [13], attractiveness to learn [2] and providing good quality content.

The aim of this paper is to study the development of IPTV (Suan Dusit Internet Broadcasting: SDIB) to mobile IPTV and the evaluation of implications of the mobile IPTV prototype in education.

\section{RELATE WORK}

Research on mobile IPTV was further developed from the IPTV of Suan Dusit Internet Broadcasting systems (SDIB). The IPTV has goals of increasing educational opportunities for students in rural areas and to support lifelong learning for adult education throughout Thailand. It broadcasts four channels twenty-four hours a day with the content being transmitted both as audio and video (live and video on demand) [3-4]. The IPTV system has been implemented and used in 80 pilot schools. The data of an evaluation of the IPTV system was collected from questionnaires and interviews. The results found that IPTV users were highly satisfied with the content, set top boxes, television LCD, and overall IPTV systems [5]. Finally, an IPTV strategy plan 2010-2015 was developed. Table 1 shows the SWOT analysis of the IPTV system [5]. 
Table 1: SWOT analysis of IPTV system

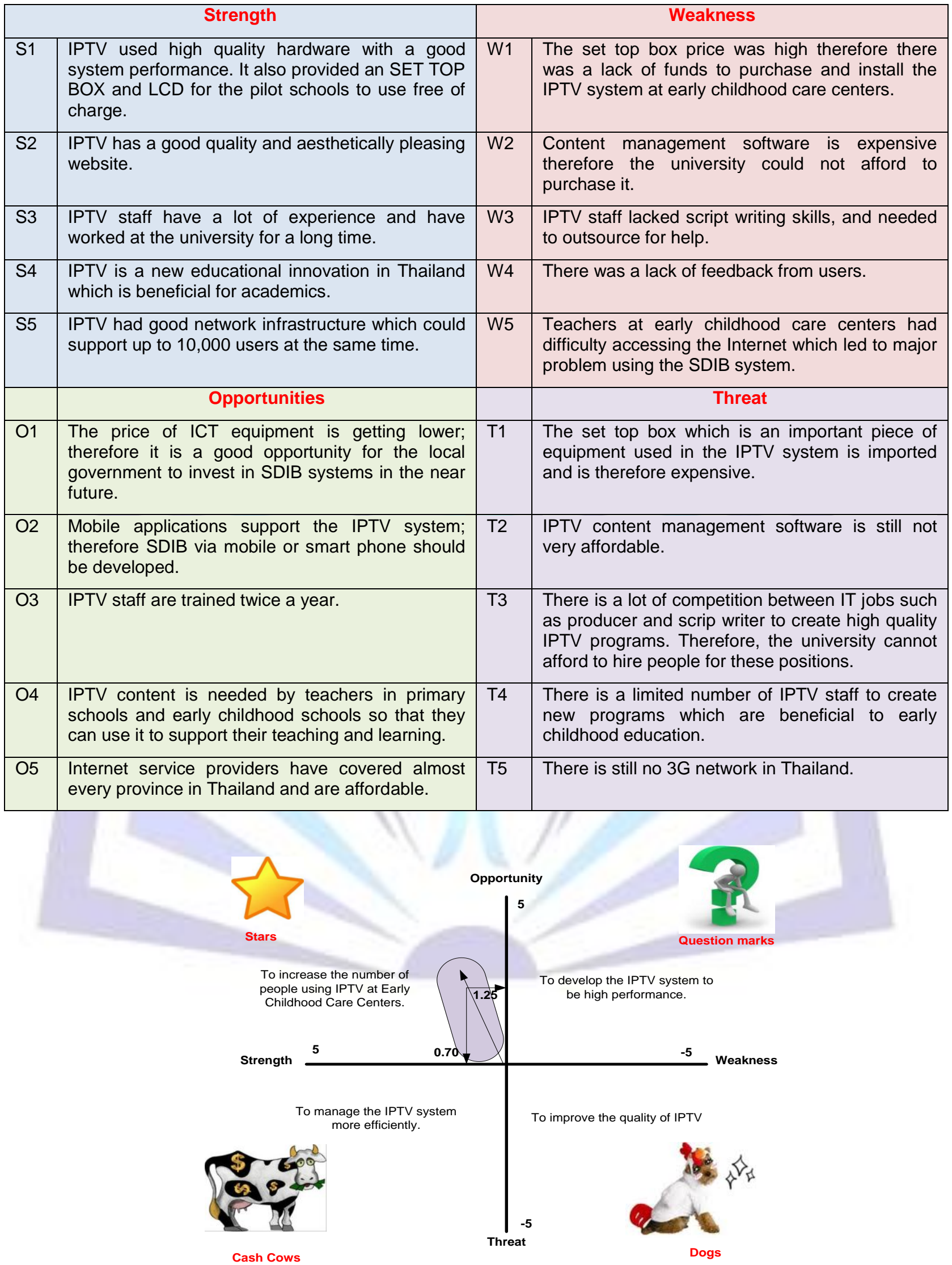

Figure 1: BCG Matrix of IPTV system 


\section{IPTV Strategies}

1. Organizational strategies

- $\quad$ To increase the number of people using IPTV at early childhood care centers.

- $\quad$ To manage the IPTV system more efficiently.

- $\quad$ To improve the IPV system so it is high performance.

- $\quad$ To improve the quality of IPTV.

2. Functional strategies:

- To promote IPTV for teachers in early childhood centers so that they can use and utilize the knowledge gained.

- To produce more early childhood programs.

- To improve the management process in order for it to be of higher efficiency and quality.

- $\quad$ To support research and development in IPTV in order for it to be of higher efficiency and quality.

- To improve the quality of IPTV content.

- To maintain IPTV equipment for prompt use.

3. There were 15 projects in the IPTV strategic plan:

1. The acquisition of IPTV equipment by early childhood centers.

2. To develop mobile IPTV applications for the iPad and smart phones.

3. To develop the competency of IPTV staff, so that they can work using the One Stop Service.

4. To publicize IPTV by using social networks and new media.

5. To set up an IPTV call center to receive feedback from users.

6. To broadcast IPTV via satellite.

7. To acquire a high volume of set top boxes.

8. To develop IPTV content management programs by using freeware.

9. To implement the quality standard ISO9001:2008

10. To hold a contest between students for SDIB programs or short movies

11. To set up a set top box factory in Thailand.

12. To promote more effective communication between IPTV users.

13. To help IPTV users in rural areas to access the Internet via satellite.

14. To outsource the IPTV program's scripts.

15. To maintain IPTV equipment.

\section{MOBILE IPTV DEVELOPMENT}

\section{Educational Framework}

The mobile IPTV project was developed by expanding the IPTV system related to the strategy plan of IPTV. A Mobile IPTV system can be seen as part of a mobile learning system (m-Learning).

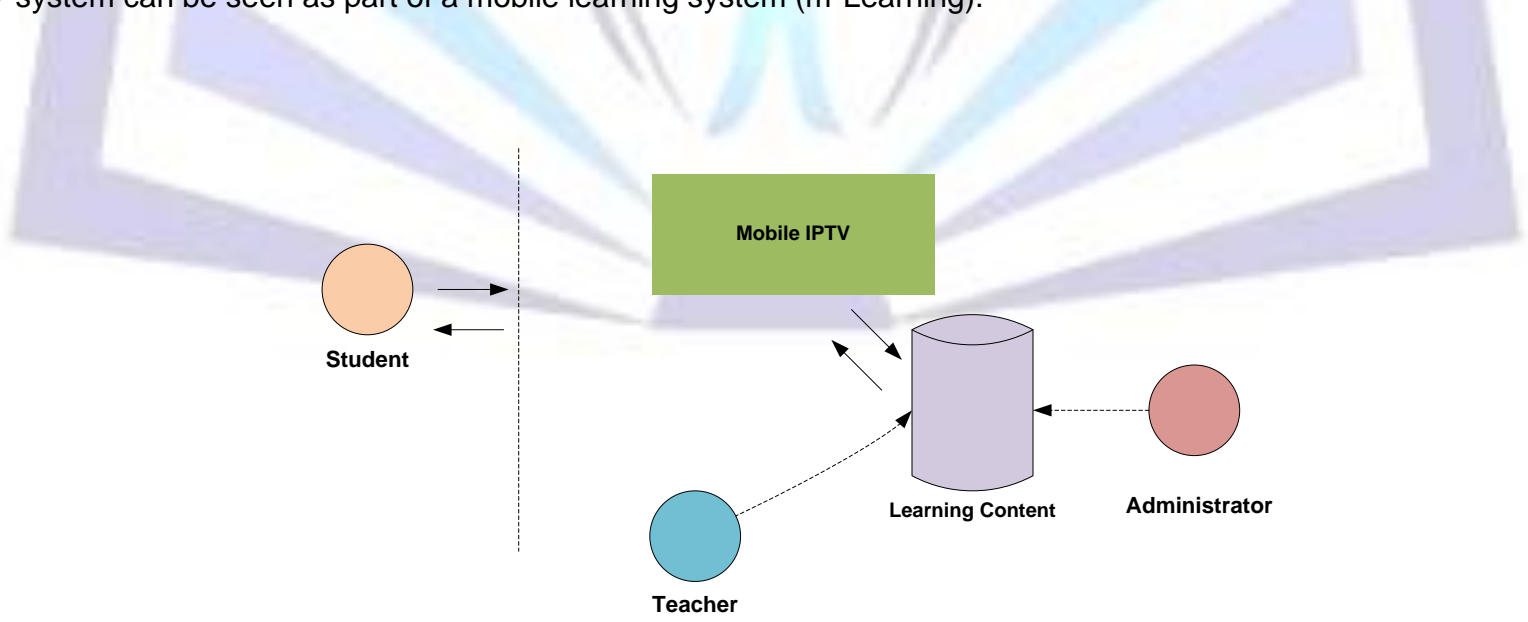

Figure 2: Mobile IPTV educational system model

Figure 2 depicts the architecture of an educational system model using a mobile IPTV system. During the educational process the student interacts with the teacher while simultaneously using mobile devices. The learning content is provided on a mobile IPTV system uploaded by a teacher or administrator. 


\section{Mobile IPTV Concept}

Mobile IPTV was designed to support senders and receivers. Currently, user created content (UCC) is becoming popular on the Internet, with any user being able to create their own content and provide it to the Mobile IPTV [10-11]. The mobile IPTV was designed to support a functional IPTV terminal device (e.g. smart phone, PDA, iPad, set top box) with information capabilities before delivering content. Moreover, it can deliver several optional versions to be selected according to the capabilities of the mobile equipment receiving the content (e.g. access rates, resolution, and supported formats) [10-11]. Mobile IPTV was designed to support four channels as with IPTV.

\section{Prototyping}

The mobile TV application was developed by following concepts of prototype [21]. Figure 3 shows the steps in prototyping mobile TV application development.

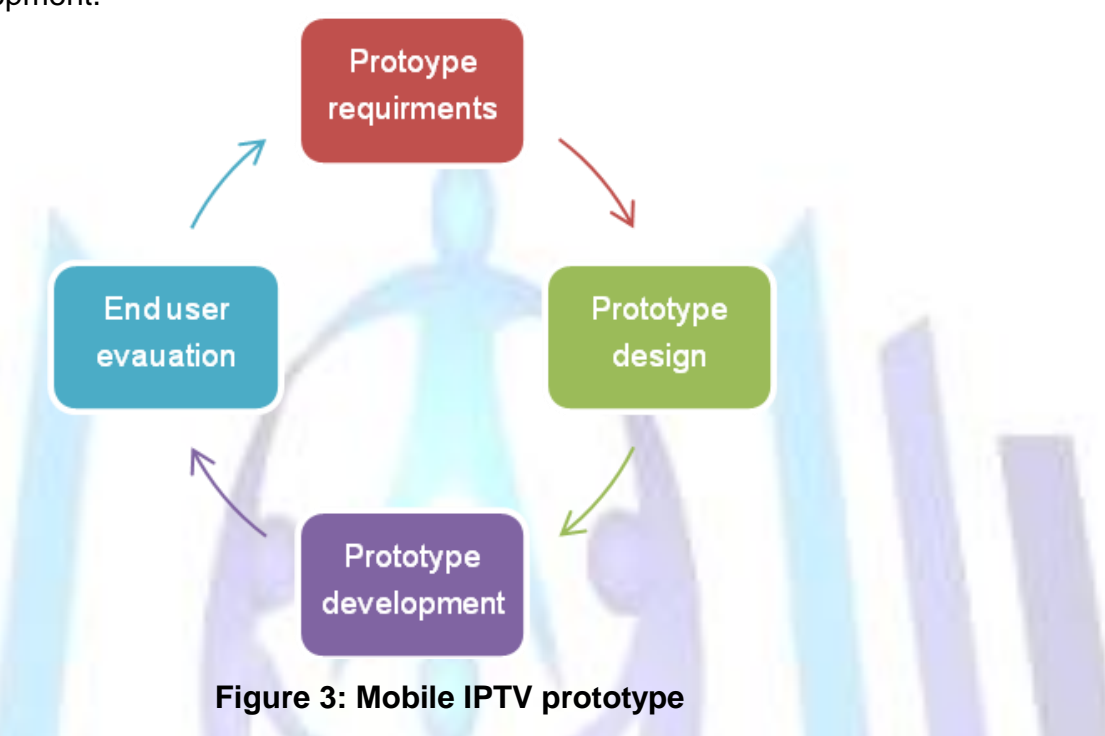

1. Prototype requirements identify the capability of the mobile IPTV system. It identifies user requirements by collecting data from interviewing students and teachers who will use the mobile broadcast system.

2. Design an initial prototype by using tools for a rapidly mobile broadcast application. This stage the mobile IPTV prototype considers how to deliver educational content and providing the functional requirement and usage workflow of the prototype.

3. Implement the mobile IPTV prototype to be used for 10 weeks by teachers and students.

4. End users evaluate the mobile IPTV prototype. The evaluation phase refers to feedback assessment and continuous improvement of the education process.

\section{Users}

Mobile IPTV has been designed to support various types of users as follows:

- Channel 1 (children): Users will be teachers in early childhood care centers around Thailand. Furthermore, the audience includes parents, kindergarten school teachers and researchers who are interested in studying early childhood education.

- Channel 2 (self-study): Users will be students who are studying at Suan Dusit Rajabhat University.

- Channel 3 (variety): Users will be students, teachers, university staff, and people who are interested in the programs.

- Channel 4 (radio): Users will be people who have low speed internet access.

\section{Content}

Content used for testing the mobile IPTV prototype from IPTV was created by users. Users of this prototype were teachers and 150 students who are studying strategic information planning for organizations at the Faculty of Science \& Technology at Suan Dusit Rajabhat University during the first 10 weeks of semester one in the academic year 2013. Students produced content for their project developing strategic planning for the organization in video files. Teachers produced content, which connects to the mobile application, about a case study of strategic information systems in various types such as text, pictures, graphics, video and audio provided on the website. 


\section{Screen design}

Screens were designed for supporting wired mobile screens. Figure 4 shows an example of screen designs.

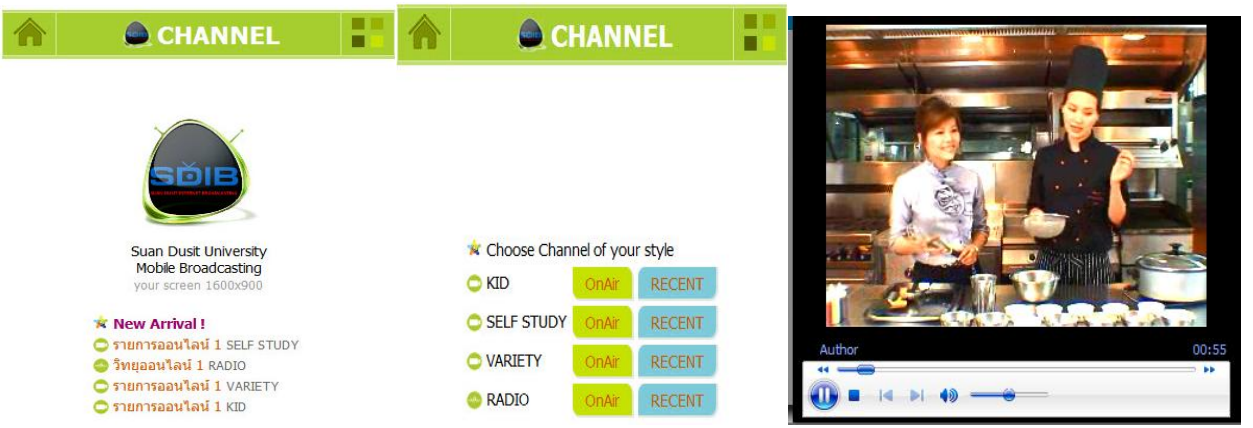

Figure 4: Example of Mobile IPTV screen design

The development of the mobile IPTV involves several technical issues [11] (shown in Table 2).

Table 2: Mobile IPTV system requirement

\begin{tabular}{|l|l|l|}
\hline \multicolumn{1}{|c|}{ Feature } & \multicolumn{1}{|c|}{ Requirement details } & \multicolumn{1}{|c|}{ Prototype mobile IPTV } \\
\hline $\begin{array}{l}\text { Content } \\
\text { management }\end{array}$ & $\begin{array}{l}\text {-Creates new content management } \\
\text { systems which support bandwidth requests } \\
\text { and congestion control capabilities. }\end{array}$ & -Creates new content management system. \\
\hline IPTV content & $\begin{array}{l}\text {-Delivers content in several optional } \\
\text { versions to be selected according to the } \\
\text { capabilities of the IPTV terminal receiving } \\
\text { the content. }\end{array}$ & $\begin{array}{l}\text {-The system supports content delivery in } \\
\text { access rate, resolution and support formats. } \\
\text {-Provides 4 channels } \\
\text {-Users can create their own content and send } \\
\text { it through the system. }\end{array}$ \\
\hline $\begin{array}{l}\text { IPTV terminal } \\
\text { device }\end{array}$ & $\begin{array}{l}\text {-Supports various types of terminal devices } \\
\text {-Provides information regarding its } \\
\text { bandwidth availability. }\end{array}$ & $\begin{array}{l}\text {-Supports smart phone, PDA, iPad, smart TV } \\
\text {-Provides information regarding bandwidth } \\
\text { availability. }\end{array}$ \\
\hline IPTV architecture & $\begin{array}{l}\text {-Allows delivery of IPTV over different } \\
\text { access networks. } \\
\text {-Allows delivery of IPTV services to any } \\
\text { devices. }\end{array}$ & $\begin{array}{l}\text {-Allows delivery of IPTV over different access } \\
\text { networks such as cable, optical, xDSL, and } \\
\text { wireless. } \\
\text {-Allows delivery of IPTV services of any mobile } \\
\text { device such as smart phone, PDA, smart TV } \\
\text { and set top box. }\end{array}$ \\
\hline
\end{tabular}

\section{Development Tools}

Mobile TV was designed using several tools that were integrated for development. Figure 5 shows the components of mobile IPTV that were constructed.

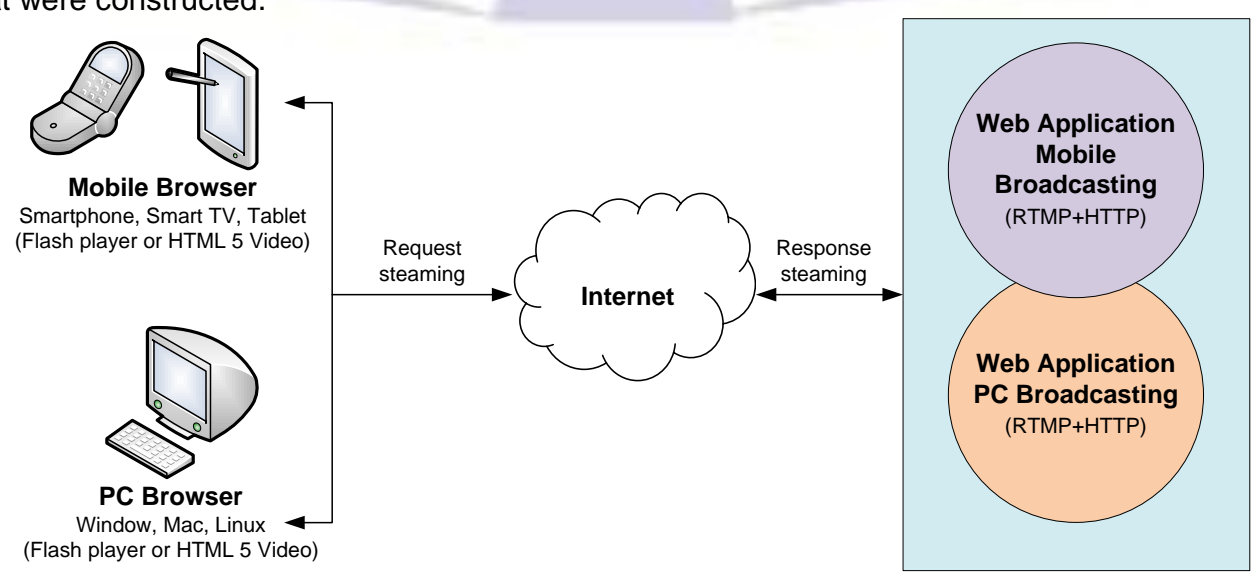

Figure 5: Mobile IPTV application structure 
1. Device: the mobile IPTV application can be broadcast on PCs, tablets (iPad, Galaxy Tab, HP Touchpad), smart phones and smart TVs (iPhone, Samsung, BlackBerry, Nokia, HTC, Sony Internet TV)

2. Browser: an application used for connecting to the Internet. This mobile broadcast application was designed for supporting both browsers on PCs (Internet Explorer, Firefox, Safari, Chrome) and browsers on mobiles (Safari on iOS, Android, Internet Explorer Mobile). The mobile application supports HTML 5 and H.264 MGS [21], which are effective for TV video files. Moreover, the mobile TV was designed to support various types of displays.

3. Table 3 shows the system was designed for supporting both high and low quality video file types for mobile TV.

4. Table 4 shows the system was designed for supporting PC and mobile audio in single quality.

Table 3: Mobile video widescreen (16:9)

\begin{tabular}{|l|l|l|l|l|l|l|l|}
\hline Quality & Width & Height & Audio Bit rate & Total Bit rate & Mime Type & Frame Rate & H.264 Profile \\
\hline High Quality & 427 & 240 & $40 \mathrm{k}$ & $600 \mathrm{kbps}$ & MP4 & $29.97 \mathrm{fps}$ & BASELINE \\
\hline Low Quality & 320 & 180 & $40 \mathrm{k}$ & $300 \mathrm{kbps}$ & MP4 & $29.97 \mathrm{fps}$ & BASELINE \\
\hline
\end{tabular}

Table 4: PC and mobile audio

\begin{tabular}{|l|l|l|l|l|}
\hline Quality & Sample Rate & Bit rate & Channels & Codec \\
\hline Single Quality & 22050 & $40 \mathrm{k}$ & stereo & MPEG-4 AAC \\
\hline
\end{tabular}

5. Streaming Sever: used for transmitting video and audio types throughout the Internet. This mobile application was designed to support Flash Media Server (FMS) which passes the RTMP protocol. The result of testing FMS compared with Wowza and Red5 found that FMS has a high performance and the interfaces were user friendly.

6. Encoder: used for converting and compressing video files and audio files to the correct format. Encoder software is used along with live streaming, but for VDO on demand streaming could be used for other software encoding as follows:

- FMLE (Adobe Media Live Encoder) is software used along with FMS for encoding into multi bandwidths.

- FFMPEG is open source software using a command line.

- WireCast is software that works with FMLE and FMPEG. It adds various special effects and encodes video files. It is different from;

- FMLE that must connect with equipment for developing photographs.

The result of testing found that FMLE works along with FMS; therefore it was used for developing mobile TV applications.

7. Protocol: is the format of sending information via the Internet. MMS (Microsoft Media Sever) using Window Media Player for displaying video and audio files. Flash Media Sever uses RTMP for displaying video and audio. The mobile broadcast application was designed to use RTMP protocol and HTTP Live streaming to support mobile TV.

8. Player: is the software for playing multimedia files but does not support flash players (iPhone, iPod, and iPad). A solution to solve this problem was found by using HTML 5 Video with supporting Safari on iOS with version 1.0. Therefore, the protocols developing mobile TV applications were integrated with HTTP through Flash Player API + HTML 5 Video.

A summary of tools for developing a mobile TV application are as follows:

- OS: Windows 200864 bit

- Web server: IIS7.

- $\quad$ Sever scrip: ASP.NET 2+

- Client scrip: Java script, HTML 5, CSS

- Database: MySQL 5

- $\quad$ Stream sever: FMS 4.5

- Encoder: FMLE 3.2

- $\quad$ Flash play API: Strobe media player 


\section{MOBILE IPTV IN THE CLASSROOM}

A Mobile IPTV prototype was used with 150 third-year students who enrolled in a 10 week Strategic Information Planning for Organization course in information technology program at the Faculty of Science \& Technology at Suan Dusit Rajabhat University.

The experiment was run as follows: Firstly, the students were told to access the platform on their mobile device, study the content topics and watch the video about the strategic information system case study. While they were using the Mobile IPTV system their actions and navigation times where recorded for further analysis. After students developed their group project case study, they uploaded their video presentation to YouTube and linked to the Mobile IPTV system. During the learning process observations and in depth-interviews were conducted. The evaluation process aimed to gather user's feedback regarding mobile phones in learning, attitudes towards using mobile phones in learning, an evaluation of IPTV systems and an evaluation of the mobile IPTV system.

There were five parts of the survey as follows:

Part I Student demographic (7 questions, Check-list)

Part II Student's behavior using mobile phones in learning (12 questions, 5 Likert scale)

Part III Student's attitude towards using mobile phones in learning (12 questions, 5 Likert scale)

Part IV the IPTV system evaluation (15 questions, 5 Likert scale)

Part V The mobile IPTV system evaluation (15 questions, 5 Likert scale)

The survey ran the Cronbach Alpha value of 0.902 which is greater than 0.9 , meaning that reliability level is excellent.

\section{RESULTS}

\section{The demography of students}

The result of demography of the students is shown in tables $5-11$.

Table 5:Gender

\begin{tabular}{|l|c|c|}
\hline & Frequency & Percent \\
\hline Male & 95 & 63.3 \\
\hline Female & 55 & 36.7 \\
\hline Total & 150 & 100.0 \\
\hline
\end{tabular}

Table 5 depicting the result of gender found that 95 students $(63.3 \%)$ were male and 55 students (36.7 \%) were female.

Table 6: Age

\begin{tabular}{|c|c|c|}
\hline Age & Frequency & Percent \\
\hline $15-18$ & 2 & 1.3 \\
\hline $19-21$ & 139 & 92.7 \\
\hline $22-25$ & 9 & 6.0 \\
\hline Total & 150 & 100.0 \\
\hline
\end{tabular}

Table 6 depicting the result of range of age found that 139 students (92.7\%) are aged between 19-21 year, 9 students $(6 \%)$ are aged in between $22-25$ years and 2 students are aged between $15-18$ years.

Table 7: GPA

\begin{tabular}{|c|c|c|}
\hline GPA & Frequency & Percent \\
\hline $2.01-2.50$ & 43 & 29.9 \\
\hline $2.51-3.00$ & 77 & 53.5 \\
\hline $3.01-3.50$ & 18 & 12.5 \\
\hline $3.51-4.00$ & 6 & 4.2 \\
\hline
\end{tabular}


Table 7 depicting the result of range of age found that 139 students (92.7\%) are aged in between 19-21 years, 9 students $(6 \%)$ are aged between $22-25$ years and 2 students are aged between $15-18$ years.

Table 8: Type of mobile phone used

\begin{tabular}{|l|c|c|}
\hline $\begin{array}{l}\text { Mobile } \\
\text { Phone }\end{array}$ & Frequency & Percent \\
\hline iPhone & 65 & 43.9 \\
\hline Samsung & 43 & 29.1 \\
\hline Nokia & 14 & 9.5 \\
\hline Imobile & 2 & 1.4 \\
\hline Other & 24 & 16.2 \\
\hline Total & 148 & 100.0 \\
\hline
\end{tabular}

Table 8 depicts the result of type of mobile phone used found that mostly students used iPhone (43.9\%), secondly they used Samsung (29.1\%) and third other brands (16.2\%).

Table 9: Internet use per day

\begin{tabular}{|c|c|c|}
\hline $\begin{array}{c}\text { Internet } \\
\text { use } \\
\text { Hours/day }\end{array}$ & Frequency & Percent \\
\hline$>1$ hours & 10 & 6.7 \\
\hline $1-3$ hours & 22 & 14.7 \\
\hline $4-5$ hours & 44 & 29.3 \\
\hline $6-7$ hours & 46 & 30.7 \\
\hline$<8$ & 28 & 18.7 \\
\hline Total & 150 & 100.0 \\
\hline
\end{tabular}

Table 9 depicting the result of Internet use per day found that mostly students spent $6-7$ hours/day $(30.7 \%)$, second spent 4-5 hours/day (29.3\%) and third more than 8 hours/day (18.7\%).

Table 10: Payment of mobile phone

\begin{tabular}{|c|c|c|}
\hline Payment & Frequency & Percent \\
\hline Prepaid & 76 & 50.7 \\
\hline Postpaid & 69 & 46.0 \\
\hline Other & 5 & 3.3 \\
\hline Total & 150 & 100.0 \\
\hline
\end{tabular}

Table 10 depicting the result of methods of mobile phone payment found that mostly students used prepaid (50.7\%) and using postpaid (46.0\%).

Table 11:Mobile phone package

\begin{tabular}{|l|r|r|}
\hline Package & Frequency & Percent \\
\hline Call only & 47 & 31.3 \\
\hline Call+SMS & 13 & 8.7 \\
\hline Call+SMS+Internet & 90 & 60.0 \\
\hline Total & 150 & 100.0 \\
\hline
\end{tabular}


Table 11 depicting the results of mobile phone packages found that mostly students used Call+SMS+Internet $(60 \%)$, second usedcall only (31.3\%) and Call+SMS (8.7\%).

\section{Student's behavior using mobile phone in learning}

Table 12: Student's behavior using mobile phones in learning

\begin{tabular}{|c|c|c|}
\hline Student's behavior using mobile phones in learning & Mean & SD \\
\hline 1. Using mobile phone to take pictures during lectures & 2.98 & 1.17 \\
\hline 2. Using mobile phones to make notes or appointments during study & 3.19 & 0.95 \\
\hline 3. Using mobile phones to record lectures & 3.07 & 0.98 \\
\hline 4. Using mobile phones to communicate with classmates & 4.03 & 0.93 \\
\hline 5. Using mobile phones to communicate with lecturer & 2.81 & 1.04 \\
\hline $\begin{array}{l}\text { 6. Using mobile phones to access the information system provided by the } \\
\text { university }\end{array}$ & 3.43 & 1.03 \\
\hline 7. Using mobile phones for searching information to do homework & 3.61 & 1.10 \\
\hline 8. Using mobile phones to access the university Wi-Fi & 3.82 & 0.96 \\
\hline 9. Using Facebook via mobile phone & 4.09 & 1.02 \\
\hline 10. Using Twitter via mobile phone & 2.38 & 1.35 \\
\hline 11. Using YouTube via mobile phone & 3.39 & 1.13 \\
\hline 12. Using Line via mobile phone & 3.97 & 1.40 \\
\hline
\end{tabular}

Table 12 depicting the results of student's behavior using mobile phones in learning found that students used Facebook (Mean $=4.09, \mathrm{SD}=1.02$ ), second used their mobile phone to communicate with class mates (Mean $=4.03, S D=0.93$ ), and third used Line (Mean $=3.97, \mathrm{SD}=1.40$ ) respectively.

\section{Student's attitudes towards using mobile phones in learning}

Table 13: Student's attitude towards using mobile phones in learning

\begin{tabular}{|l|c|c|}
\hline Student's behavior using mobile phones in learning & Mean & SD \\
\hline 1. Using mobile phone increased effective learning & 3.75 & 0.89 \\
\hline 2. Sharing information on social networks can share learning experiences & 3.83 & 0.76 \\
\hline 3. Using a mobile phone is more convenient for study & 3.81 & 0.97 \\
\hline 4. A mobile phone can share information with classmates effectively & 3.99 & 0.90 \\
\hline 5. Using a mobile phone for revising lecture and learning & 3.59 & 0.89 \\
\hline 6. A mobile phone can replace a notebook computer & 3.27 & 1.10 \\
\hline 7. The university should provide mobile phones rather than notebook & 2.45 & 1.35 \\
\hline 8. The university should develop applications in m-Learning system & 3.67 & 0.98 \\
\hline
\end{tabular}

Table 13 depicts the result of student's attitudes towards use of mobile phones in learning found that students using mobile phones can share information with classmates effectively (Mean $=3.99, \mathrm{SD}=0.90$ ), second sharing information on social networks can share the learning experience (Mean $=3.83, \mathrm{SD}=0.76$ ), second and third using mobile phones more convenient for study (Mean $=3.81, \mathrm{SD}=0.97$ ), respectively. 


\section{IPTV and mobile IPTV system evaluation}

Table 14: The IPTV and mobile IPTV system evaluation

\begin{tabular}{|l|c|c|c|c|}
\hline \multicolumn{2}{|c|}{ The IPTV and mobile IPTV system evaluation } & \multicolumn{2}{|c|}{ IPTV } & \multicolumn{2}{c|}{ Mobile IPTV } \\
\cline { 2 - 5 } & Mean & SD & Mean & SD \\
\hline 1. $\quad$ Easy to access the system & 3.49 & 0.66 & 3.65 & 0.69 \\
\hline 2. $\quad$ The system is easy to use & 3.55 & 0.62 & 3.69 & 0.75 \\
\hline 3. $\quad$ The system is interesting & 3.64 & 0.77 & 3.79 & 0.69 \\
\hline 4. $\quad$ The system provides useful functions & 3.51 & 0.65 & 3.60 & 0.72 \\
\hline 5. The system supports effective Internet use & 3.59 & 0.67 & 3.59 & 0.71 \\
\hline 6. The system can broadcast multimedia effectively & 3.69 & 0.69 & 3.69 & 0.75 \\
\hline 7. The design of the website is attractive & 3.49 & 0.72 & 3.58 & 0.63 \\
\hline 8. The content on the system can be applied in self-learning & 3.51 & 0.65 & 3.59 & 0.73 \\
\hline 9. The content on the system can be applied in daily life & 3.59 & 0.72 & 3.67 & 0.70 \\
\hline 10. The content on the system is interesting & 3.65 & 0.78 & 3.64 & 0.74 \\
\hline 11. Students can revise lectures on Video on Demand & 3.49 & 0.74 & 3.65 & 0.72 \\
\hline 12. The system supports self-learning & 3.55 & 0.71 & 3.59 & 0.75 \\
\hline 13. Knowledge gained from the system can improve learning outcomes & 3.38 & 0.73 & 3.52 & 0.70 \\
\hline 14. The system can be used to share information with classmates & 3.63 & 0.68 & 3.64 & 0.76 \\
\hline 15. Overall satisfaction & 3.61 & 0.65 & 3.70 & 0.78 \\
\hline
\end{tabular}

Table 14 depicting the results of the IPTV and mobile IPTV system evaluation found that overall mobile IPTV had a higher satisfaction (Mean $=3.70$, SD. $=0.78$ ) than IPTV (Mean $=3.61$, SD. $=0.65$ ). The result found that the highest score was mobile IPTV is interesting (Mean $=3.79, \mathrm{SD} .=0.69)$, second overall mobile IPTV satisfaction $($ Mean $=3.70, \mathrm{SD} .=0.78)$ and third mobile IPTV is easy to use (Mean $=3.69$, SD. $=0.75$ ), respectively.

Here are some comments to illustrate the evaluation of IPTV and the mobile IPTV:

"We shared information about how to develop a business plan because this is new for us. We shared pictures, information, and video clips to other groups via Facebook".

"We like to watch "English More" programs on channel 3, to practice our English"

"We think every learning application should go with mobile technology because it is very convenient and easy to use, we can study everywhere and at anytime.

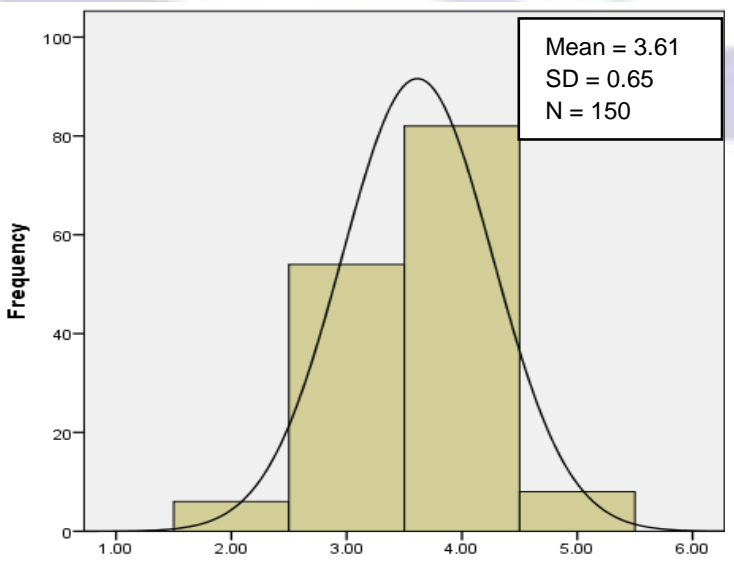

Figure 6: IPTV system overall satisfaction

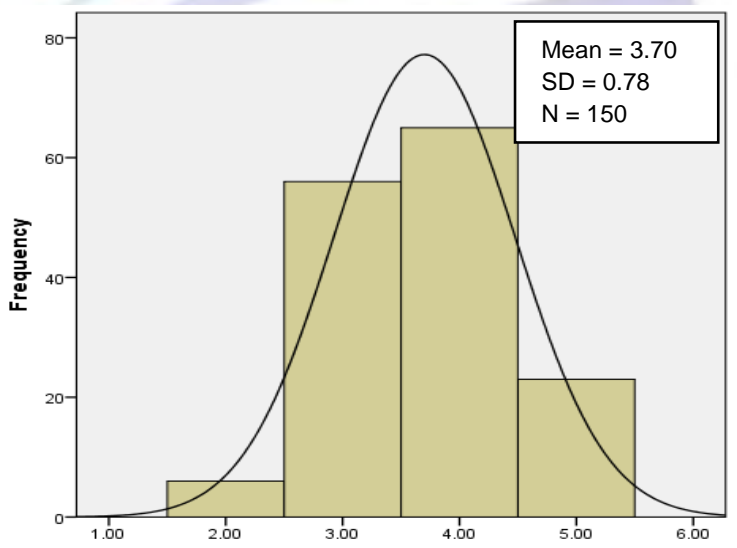

Figure 7: Mobile IPTV system overall satisfaction

Figure 7 depicting the results of the mobile IPTV system overall satisfaction (Mean $=3.70, \mathrm{SD} .=0.78$ ) is higher than the IPTV system overall satisfaction (Mean $=3.61$, SD. $=0.65)$. 
Table 15: Comparison of Statistics

\begin{tabular}{|c|c|c|c|c|}
\hline \multicolumn{5}{|c|}{ Statistics } \\
\hline & $\begin{array}{l}\text { Behavior of } \\
\text { using mobile } \\
\text { phones in } \\
\text { learning }\end{array}$ & $\begin{array}{c}\text { Attitudes } \\
\text { towards using } \\
\text { mobile phone in } \\
\text { learning }\end{array}$ & $\begin{array}{l}\text { IPTV system } \\
\text { evaluation }\end{array}$ & $\begin{array}{c}\text { Mobile IPTV } \\
\text { system } \\
\text { evaluation }\end{array}$ \\
\hline $\mathrm{N}$ & 150 & 150 & 150 & 150 \\
\hline Mean & 3.3641 & 3.5433 & 3.6133 & 3.7000 \\
\hline Median & 3.4615 & 3.6250 & 4.0000 & 4.0000 \\
\hline Std. Deviation & .64004 & .66048 & .65320 & .77503 \\
\hline Skewness & -.687 & -.896 & -.283 & .053 \\
\hline Kurtosis & .810 & .951 & -.002 & -.548 \\
\hline Minimum & 1.00 & 1.00 & 2.00 & 2.00 \\
\hline Maximum & 5.00 & 5.00 & 5.00 & 5.00 \\
\hline
\end{tabular}

Table 15 depicts the statistical evaluation approach of the four issues. Every evaluated issue has an average between 3.3 and 3.7, leading to the conclusion of high satisfaction of high quality mobile IPTV user experience. The Skewness is negative for three variables meaning the values concentrated to the higher values of the scale. Because the user experience is a psychometric evaluation it needs to test the internal consistency (reliability) of the analyzed scale distribution. The Cronbach Alpha value is 0.902 which is greater than 0.9 , meaning that reliability level is excellent.

Table 16: One-Sample Test

\begin{tabular}{|c|c|c|c|c|c|c|}
\hline \multicolumn{7}{|c|}{ One-Sample Test } \\
\hline & \multicolumn{6}{|c|}{ Test Value $=0$} \\
\hline & \multirow[t]{2}{*}{$\mathrm{t}$} & \multirow[t]{2}{*}{$\mathrm{df}$} & \multirow[t]{2}{*}{ Sig. (2-tailed) } & \multirow[t]{2}{*}{ Mean Difference } & \multicolumn{2}{|c|}{$\begin{array}{l}\text { 95\% Confidence Interval of the } \\
\text { Difference }\end{array}$} \\
\hline & & & & & Lower & Upper \\
\hline IPTV & 67.750 & 149 & .000 & 3.61333 & 3.5079 & 3.7187 \\
\hline Mobile IPTV & 58.469 & 149 & .000 & 3.70000 & 3.5750 & 3.8250 \\
\hline
\end{tabular}

Table 16 depicts the one sample test. The result found that mobile IPTV has a higher value of mean than IPTV.

Table 17: Correlation between behavior of using mobile phones in learning and attitudes towards using mobile phones in learning with IPTV

\begin{tabular}{|c|c|c|c|}
\hline & & $\begin{array}{c}\text { Behavior of using mobile } \\
\text { phone in learning }\end{array}$ & $\begin{array}{c}\text { Attitude towards of using } \\
\text { mobile phone in learning }\end{array}$ \\
\hline Kendall's tau_b & IPTV & $.328^{\prime \prime}$ & $.256^{\prime \prime}$ \\
\hline Spearman's rho & IPTV & $.396^{\prime \prime}$ & $.313^{\prime \prime}$ \\
\hline
\end{tabular}

\section{**Significant $<0.10$}

Table 17 depicts the correlation between behavior using mobile phones in learning and attitudes towards using mobile phones in learning with IPTV. The result found high significant correlation between IPTV and behavior and attitudes towards using mobile phones in learning. 
Table 18: Correlation between behavior using mobile phone in learning and attitudes towards using mobile phones in learning with mobile IPTV

\begin{tabular}{|c|c|c|c|}
\hline & & $\begin{array}{c}\text { Behavior of using } \\
\text { mobile phone in } \\
\text { learning }\end{array}$ & $\begin{array}{c}\text { Attitude towards of } \\
\text { using mobile phone in } \\
\text { learning }\end{array}$ \\
\hline Kendall's tau_b & Mobile IPTV & $.343^{\text {Nat }}$ & .328 \\
\hline Spearman's rho & Mobile IPTV & .417 & .406 \\
\hline
\end{tabular}

\footnotetext{
${ }^{* *}$ Significant $<0.10$
}

Table 18 depicts the correlation between behavior using mobile phones in learning and attitude towards using mobile phones in learning of mobile IPTV. The result found high significant correlation between mobile IPTV and behavior and attitude towards of using mobile phone in learning.

\section{CONCLUSION}

Mobile IPTV was illustrated in this paper through the development of IPTV for education. The IPTV project background was demonstrated and explained through IPTV architecture, content, implications for education and the IPTV strategic plan for education. The mobile IPTV development had several technical issues of concern including mobile IPTV concepts, requirement details, prototyping designed, users, content, development tools, screen design, and prototype implementation in pilot project. Several tools were used to develop the mobile IPTV prototype including mobile devices, browsers, streaming servers, encoders, protocol setup and players.

The mobile IPTV prototyping was designed to support content delivery that considered the access rate, resolution and supported formats. It consisted of four channels where users could create their own content, it provided information regarding bandwidth availability, and it supported a variety of outputs, smart phone, PAD, iPad, and smart TV and various types of access networks, cable, optical, wireless, ADSL, and wireless. A mobile IPTV prototype was used with 150 thirdyear students enrolled in a 10 week Strategic Information Planning for Organization course in information technology program at the Faculty of Science \& Technology at Suan Dusit Rajabhat University. The results found that the demography of the students, are mostly male (63.3\%), aged 19-21 years (95.7\%), GPA in between 2.51-3.00 (53.5\%), own an iPhone (43.9\%), use the Internet around 6-7 hours per day (30.7\%), use mobile prepaid payment (50.7\%) and employ a Call+SMS+Internet mobile package (60\%).

The results of student's behavior using mobile phones in learning found that students use Facebook (Mean $=4.09$, SD $=1.02$ ), secondly use their mobile phone to communicate with classmates (Mean $=4.03, \mathrm{SD}=0.93$ ), and third use Line (Mean $=3.97, \mathrm{SD}=1.40$ ), respectively.

The results of student's attitudes towards using mobile phones in learning found that students using mobile phones can share information with classmates effectively (Mean $=3.99$, SD $=0.90$ ), second sharing information on social networks can share learning experiences (Mean $=3.83, \mathrm{SD}=0.76$ ), second and third using a mobile phone is more convenient for study (Mean $=3.81$, SD $=0.97$ ), respectively. The result of the IPTV and mobile IPTV system evaluation found that overall the mobile IPTV was highest satisfaction (Mean = 3.70, SD =0.78) than IPTV (Mean = 3.61, SD =0.65).

Future work will focus on expanding more sophisticated Mobile IPTV architecture and technical requirements to take into account the wireless environment, and to focus on its implications for teaching and learning. It needs a streaming sever for mobile broadcasting content. Also, it needs to compete with the mobile IPTV standardization in the market such as DVBCBMS, OMA-BCAST, 3GPP-MBMS, WiMax-MBS, etc. Moreover, it also needs to convert IPTV content (more than 780 programs) to mobile IPTV content.

This mobile IPTV prototype will be used for experimenting in other subjects. When the experiment finishes, this system will be evaluated using several factors such as studying users' satisfaction, attitude and learning outcomes and developing the Mobile IPTV educational framework. The mobile IPTV application can expand to ' $m$-Learning' or 'mobile Learning' by connecting with social networks to build communication among students and teachers. Mobile IPTV will become part of life, and expand its value to increase the quality of education in the future.

\section{ACKNOWLEDGMENTS}

The author would like to thank the Office of Academic Resource and Information Technology (ARIT) at Suan Dusit Rajabhat University for providing contents and network infrastructure for testing the mobile IPTV.

\section{REFERENCES}

[1] Drake, S.D. 2008. Embracing New Generation Mobile Platforms to Solve Business Problem. A Sybase White Paper. October 2008 
[Online: http://www.techrepublic.com/whitepapers/embracing-next-generation-mobile-platforms-to-solve-businessproblems/1196229], Access 10 July, 2012.

[2] Teng, C.C. and Helps, R. 2010. Mobile Application Development: Essential New Directions for IT. In Proceedings of the $7^{\text {th }}$ International Conference on Information Technology. Las Vegas, Nevada, USA.

[3] Suanpang, P. 2012. "Internet Protocol Television (IPTV) Implication for Education". Journal of Software Engineering and Applications. Vol. 5, pp. 50-55.

[4] Suanpang, P., Termboonprasert, J.,Kantamanoon, P., and Rengitinun, S. 2010. Internet Broadcasting: An Educational Innovation for Developing Teacher in Early Childhood Care Centers All Over Thailand: Phase 1. Bangkok, Suan Dusit Rajabhat University.

[5] Suanpang, P. 2011. Internet Broadcasting: An Educational Innovation for Developing Teacher in Early Childhood Care Centers All Over Thailand: Phase 2. Bangkok, Suan Dusit Rajabhat University.

[6] Liu, Z., Wei, B. and Yu, H. 2009. IPTV, towards seamless infotainment, . In Proceedings of the $6^{\text {th }}$ IEEE Consumer Communications and Networking Conference, CCNC 2009. pp.1-5.

[7] Borge, M., Rita, P., and Pagani, M. 2011. A new conceptual framework to evaluate consumer adoption of mobile service: The case of Mobile TV. . In Proceedings of the $10^{\text {th }}$ International Conference on Mobile Business. Como, Italy.

[8] Drake, S.D. 2008.Embracing New Generation Mobile Platforms to Solve Business Problem, a Sybase White Paper.

[Online:http://www.techrepublic.com/whitepapers/embracing-next-generation-mobile-platforms-to-solve-businessproblems/1196229], Access 10 July, 2012.

[9] Teng, C.C. and Helps, R. 2010. Mobile Application Development: Essential New Directions for IT. In Proceedings of the $7^{\text {th }}$ International Conference on Information Technology. Las Vegas, Nevada, USA.

[10] Park, S., Jeong, S. H. and Hwang, C. 2008. Mobile IPTV Expanding the Value of IPTV. In Proceedings of the $7^{\text {th }}$ International Conference on Networking. ICN 2008. Cancun, Mexico, pp 296-301.

[11] Park, S. and Jeong, S. 2009. "Mobile IPTV approaches, challenges, standard and QoS support", IEEE Internet Computing, Vol. 13, No. 3 pp. 23-31.

[12] Zeadally, S. and Moustafa, H. 2011. "Internet Protocol Television (IPTV): Architecture, Trends, and Challenges", IEEE System Journal. Vol.5, No. 4, pp. 518-527.

[13] Uther, M. and Ipser, A. 2012. Design mobile language learning applications using multimedia, Implication form a small-scale prospective learner study. In Proceedings of the $7^{\text {th }}$ IEEE International Conference on Wireless, Mobile and Ubiquitous Technology in Education. Japan, pp. 202-204.

[14] Sharples,M, Taylor, J. and Vavoula, G. 2005. "Toward a Theory of Mobile Learning”, mLearner 2005, Vol 1, No. 1, pp 1-9.

[15] Montpetit, M. J., Klym, N., and Mirlacher, T. 2011. "The future of IPTV Connected, mobile, personal and social", Multimed Toosl Appl, Vol.53, pp. 519-532.

[16] Lai, X.Y., Lai, C.F., Hu, C.C., Chao, H.C., and Huang, Y. M .2011. "A personalized IPTV system with seamless video reconstruction algorithm in cloud network”. International Journal of Communication Systems, Vol. 24, pp. $1375-1387$.

[17] Bull, P. and Maccormick, C. 2012. "Mobile Learning: Integrated Text Messaging into Community College Pre-Algebra Course", E-Learning, Vol. 11, No. 3, pp. 233-245.

[18] Pocatilu, P., and Boja, C. 2009b. "Quality characteristics and metrics related to m-Learning process", Amfiteatru Economic, Vol. 11, No. 26, pp. 346-354.

[19] Naismith, L., Londsale, P., Vavoula, G., and Sharples, M. 2004. Literature Review in Mobile Technologies and Learning. University of Birmingham.

[20] Luandon, K.C., and Laudon., J.P. 2012. Management Information Systems Managing the Digital Firm, $12^{\text {th }}$ ed. Person Education: UK, pp. 531-532.

[21] Joo, H. and Song, H. 2010. H.264 MGS Coding-Based IPTV System Architecture Over WiMax Network, In Proceedings of the International Conference on Multimedia and Expo, Singapore. 


\section{Author' biography}

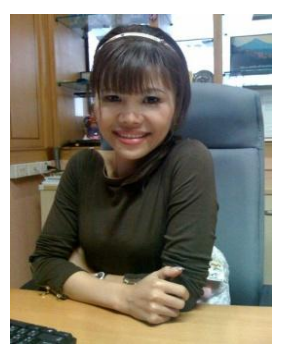

Pannee Suanpang is working as an assistant professor in the Faculty of Science \& Technology, Suan Dusit Rajabhat University. She handles professional subjects like Strategy Information Systems, Management Information Systems, System Analysis and Design, Educational Technology, Knowledge Management, e-Commerce and Technology in Tourism. She finished her Bachelor in Information Technology (BIT) and her Master of Information Systems (MIS), at Griffith University, Australia. She finished her Doctor of Technology in Science (DTech) at the University of Technology, Sydney, Australia. She is a member of the IEEE professional association 